\title{
Respiratory Support during Bronchiolitis Due to One Virus versus More Than One Virus: An Observational Study
}

\author{
Thomas Coleman ${ }^{1} \quad$ Alison Taylor ${ }^{1} \quad$ Helen Crothall ${ }^{1}$ \\ 1 Paediatric Intensive Care Unit, Division of Critical Care Services, John \\ Hunter Children's Hospital, Newcastle, New South Wales, Australia \\ J Pediatr Intensive Care 2019;8:204-209.
}

\author{
F. Eduardo Martinez ${ }^{1}$
}

Address for correspondence F. Eduardo Martinez, MD, FCICM, Paediatric Intensive Care Staff Specialist, John Hunter Children's Hospital, Locked Bag 1, Hunter Region Mail Centre, Newcastle, NSW 2310, Australia (e-mail: ed.martinez@health.nsw.gov.au).

\begin{abstract}
Keywords

- infant

- bronchiolitis

- viruses

- critical care

Bronchiolitis is common during infancy and frequently leads to pediatric intensive care unit (PICU) admission. This study aimed to determine if there is a difference in the duration of respiratory support when bronchiolitis is due to one virus or more than one virus. This is a retrospective, observational study of cases admitted to PICU with confirmed bronchiolitis. There were 306 cases analyzed, 70\% (215/306) were infected by a single virus and $30 \%(91 / 306)$ were infected with more than one virus. Both groups had similar duration of respiratory support and PICU length of stay (LOS). Hospital LOS was longer for the group with more than one virus.
\end{abstract}

\section{Introduction}

Viral bronchiolitis is one of the most common causes for nonelective admission to the pediatric intensive care unit (PICU) worldwide. ${ }^{1}$ According to recent data, about $5.9 \%$ of bronchiolitis presentations require admission to PICU and that $80 \%$ of those require some form of ventilatory support while there. ${ }^{2}$ The viruses responsible for these infections are many. ${ }^{3}$ Respiratory syncytial virus (RSV), followed by rhinovirus, seem to be the most prevalent pathogens. ${ }^{3-5}$ Influenza, parainfluenza, metapneumovirus, adenovirus, and coronavirus are also frequently identified and might be responsible for greater illness severity. ${ }^{3}$ The treatment for bronchiolitis, irrespective of the pathogen, is supportive and includes different levels of respiratory assistance that range from oxygen delivered via lowflow nasal cannula to invasive mechanical ventilation (IMV). ${ }^{6}$

The detection of multiple respiratory viruses in infants with bronchiolitis is common, with multiple virus infection seen in 5 to $20 \%$ of presentations. ${ }^{1,7}$ The clinical significance of coinfection remains controversial. ${ }^{8,9}$ Some studies argue that multiple virus infections cause a more severe course of illness with more frequent admissions to PICU, longer hospital length of stay (LOS), and the need for more intensive respiratory support. ${ }^{1,8,10}$ Other studies suggest that infec- tion with more than one virus produces a course of illness that is no different, or even less severe, to that of infections with only one virus. ${ }^{4,8,11}$

Despite the abundant literature around this topic, there are few descriptions about the specifics of illness progression once in PICU. ${ }^{12}$ With many different respiratory assistance delivery systems now available, it would be useful to know what type and how much of that respiratory support patients with bronchiolitis due to one virus require when compared to bronchiolitis due to more than one virus. ${ }^{13}$ This could potentially help clinicians anticipate what degree of respiratory support infants will need when admitted to PICU due to viral bronchiolitis.

This study took a sample of children younger than 1 year of age, admitted to PICU, with a confirmed diagnosis of bronchiolitis through polymerase chain reaction (PCR). Cases were then separated into two groups: one where infants had bronchiolitis due to only one virus and a second group where cases were due to more than one virus (two or more). The aim of this study was to determine whether there was a difference in the overall duration of respiratory support via any means of delivery between these two groups. The secondary aims of this study were to determine whether there was a difference between the two groups in: (1) the duration of respiratory received

March 7, 2019

accepted after revision

April 11, 2019

published online

May 29, 2019
Copyright (c) 2019 by Georg Thieme

Verlag KG, Stuttgart . New York
DOI https://doi.org/ 10.1055/s-0039-1691839. ISSN 2146-4618. 
support depending on the type of support used, (2) PICU LOS, (3) hospital LOS, (4) the rate of confirmed superimposed bacterial coinfection, and (5) the rate of empirical use of antibiotics.

\section{Methods}

This is a retrospective, observational, single-center study of infants of 1 year of age or less. These children had a diagnosis of viral bronchiolitis between July 1, 2007, and July 1, 2017, and where admitted to PICU at The John Hunter Children's Hospital, which is a tertiary-referral, university-affiliated, pediatric center in Newcastle, New South Wales, Australia.

Bronchiolitis was defined as a clinical syndrome occurring in infants characterized by upper respiratory symptoms followed by lower respiratory infection with inflammation, which resulted in wheezing and/or crackles. ${ }^{14-17}$ Patients screened were identified from the hospital's PICU electronic database. Patients included were 1 year of age or less at the time of admission to PICU, had an International Classification of Diseases 10th edition diagnostic criteria for bronchiolitis (code J21), and had microbiological evidence of viral respiratory tract infection on nasopharyngeal aspirate (NPA) through PCR assay. Patients were excluded from final analysis if they did not have confirmed viral infection through PCR or if medical records or PICU data were unavailable.

Ethics approval was obtained from the hospital's Human Research Ethics Committee. Demographic data were collected on age, gender, prematurity, birth weight, and comorbidities. Clinical data were collected on the presence of fever on presentation, total number of viruses detected through PCR on NPA, virus subtypes, duration of respiratory support via high-flow nasal cannula (HFNC), bubble continuous positive airway pressure (bCPAP) ventilation, and IMV, as well as PICU and hospital LOS. Data were also collected on the rate of bacterial infections found on cultures and the rate of use of empirical antibiotics.

Descriptive statistics are presented with medians and interquartile ranges (IQRs). Statistical analysis was carried out with the assumption that the data were of nonparametric distribution and Mann-Whitney U-test was used to determine whether there was a statistically significant difference between groups. Contingency tables were analyzed using Fisher's exact test. A $p$-value of $<0.05$ was considered significant.

\section{Results}

During the time period studied, there were 336 infants screened who were 1 year of age or less, were admitted to PICU, and had a diagnosis of viral bronchiolitis. Of these, 7 were excluded for incomplete data sets and 23 were excluded due to lack of pathogen identified on NPA PCR testing. This left 306 cases that were analyzed. Of the 306 infants included in the final analysis, $70.3 \%(215 / 306)$ had a single virus isolated on NPA and 29.7\% (91/306) had more than one virus isolated (-Fig. 1).

Demographic data were comparable between the two groups with no statistically significant difference between them in any of the categories. Additionally, the two groups had comparable gestational age, rate of low birth weight, mode of delivery, rate of breastfeeding at any time in life, and rate of completed immunization for age. Comorbidities were also comparable between the two groups with both displaying equal rates of congenital heart disease and chronic lung disease (-Table 1).

When looking at the primary outcome of duration of respiratory support via any mode, there was no difference between the two groups with a median duration of respiratory

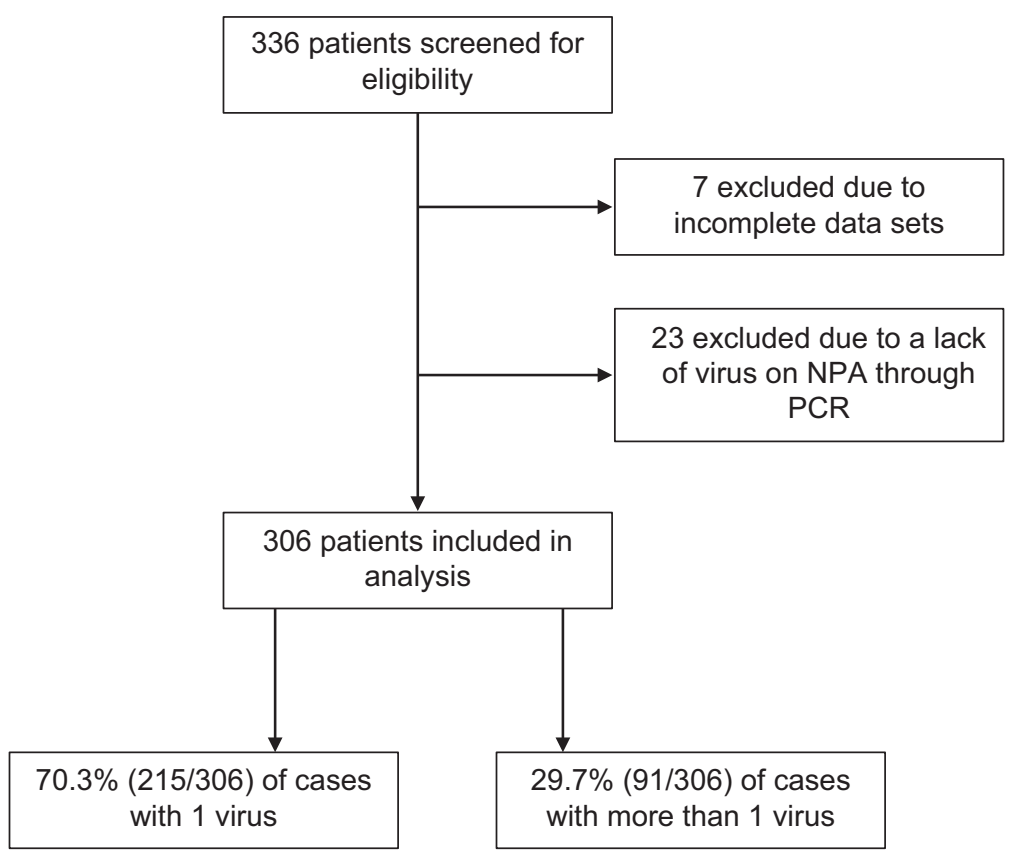

Fig. 1 Screening and inclusion of infants admitted to pediatric intensive care unit (PICU), less than 1-year-old, and with bronchiolitis due to one virus or more than one virus. 
Table 1 Demographic characteristics of infants admitted to PICU, less than 1-year-old, and with bronchiolitis due to one virus or more than one virus

\begin{tabular}{|c|c|c|c|}
\hline Characteristics & $\begin{array}{l}\text { One virus } \\
(n=215)\end{array}$ & $\begin{array}{l}\text { More than } \\
\text { one virus } \\
(n=91)\end{array}$ & $p$-Value \\
\hline \multicolumn{4}{|l|}{ Age (d) } \\
\hline Median (IQR) & $102(44-226)$ & $111(54-187)$ & 0.73 \\
\hline \multicolumn{4}{|l|}{ Gender } \\
\hline Male & $56 \%(121 / 215)$ & $67 \%(61 / 91)$ & \multirow[t]{2}{*}{0.10} \\
\hline Female & $43 \%(94 / 215)$ & $33 \%(30 / 91)$ & \\
\hline \multicolumn{4}{|c|}{ Gestational age at birth (wk) } \\
\hline Median (IQR) & $38(36-39)$ & $37.8(36-39)$ & 0.82 \\
\hline \multicolumn{4}{|c|}{ Birth weight $<2.5 \mathrm{~kg}$} \\
\hline$<2.5 \mathrm{~kg}$ & $17 \%(37 / 215)$ & $23 \%(21 / 91)$ & \multirow[t]{2}{*}{0.26} \\
\hline$\geq 2.5 \mathrm{~kg}$ & $83 \%(178 / 215)$ & $77 \%(70 / 91)$ & \\
\hline \multicolumn{4}{|l|}{ Mode of delivery } \\
\hline Vaginal & $55 \%(118 / 215)$ & $49 \%(45 / 91)$ & \multirow[t]{2}{*}{0.45} \\
\hline Caesarean & $45 \%(97 / 215)$ & $51 \%(46 / 91)$ & \\
\hline \multicolumn{4}{|c|}{ Breastfed at any time during life } \\
\hline Yes & $55 \%(90 / 163)$ & $62 \%(56 / 91)$ & \multirow[t]{2}{*}{0.36} \\
\hline No & $45 \%(73 / 163)$ & $38 \%(35 / 91)$ & \\
\hline \multicolumn{4}{|c|}{ Immunizations up to date } \\
\hline Yes & $92 \%(188 / 205)$ & $98 \%(81 / 83)$ & \multirow[t]{2}{*}{0.11} \\
\hline No & $8 \%(17 / 205)$ & $2 \%(2 / 83)$ & \\
\hline \multicolumn{4}{|c|}{ Congenital heart diseases } \\
\hline Yes & $4 \%(9 / 215)$ & $4 \%(4 / 91)$ & \multirow[t]{2}{*}{1.00} \\
\hline No & $96 \%(206 / 215)$ & $96 \%(87 / 91)$ & \\
\hline \multicolumn{4}{|c|}{ Chronic lung diseases } \\
\hline Yes & $3 \%(7 / 215)$ & $0 / 91$ & \multirow[t]{2}{*}{0.11} \\
\hline No & $97 \%(208 / 215)$ & $91 / 91$ & \\
\hline \multicolumn{4}{|c|}{ Length of illness at presentation } \\
\hline Median (IQR) & $3(2-4)$ & $3(2-4)$ & 0.84 \\
\hline
\end{tabular}

Abbreviations: IQR, interquartile range; PICU, pediatric intensive care unit.

support of 45 hours (IQR: 26-76) in the one virus group and 39 hours (IQR: 24-66) in the more than one virus group ( $p$ value $=0.14)$. HFNC was the most common mode of respiratory support used, with $94 \%$ (287/306) of all cases receiving it, followed by bCPAP with 65\% (200/306) receiving it and with IMV being the mode least used with only $9 \%$ (26/306) of infants receiving it. Duration of HFNC, bCPAP, and IMV was also comparable between the two groups ( - Table $\mathbf{2}$ ).

The median PICU LOS was 2.1 days (IQR: $1-3$ ) in the single virus group and 3 days (IQR: $1-4$ ) in the more than one virus group $(p=0.06)$. The median duration of hospital LOS was 4 days (IQR: $3-6$ ) in the one virus group and 5 days (IQR: $4-9$ ) in the more than one virus group $(p=0.03)$.

There was no statically significant difference in the rates of HFNC, bCPAP, or IMV that infants received between the two groups (-Table 3 ).
Table 2 Duration of respiratory support and lengths of stay for cases with one virus compared to cases with more than one virus

\begin{tabular}{|c|c|c|c|c|}
\hline & All cases & One virus & $\begin{array}{l}\text { More than } \\
\text { one virus }\end{array}$ & $p$-Value \\
\hline \multicolumn{5}{|c|}{ Duration of respiratory support (h) } \\
\hline $\begin{array}{l}\text { Median } \\
\text { (IQR) }\end{array}$ & $\begin{array}{l}44 \\
(25-73)\end{array}$ & $\begin{array}{l}45 \\
(26-76)\end{array}$ & $\begin{array}{l}39 \\
(24-66)\end{array}$ & 0.14 \\
\hline \multicolumn{5}{|c|}{ HFNC ventilation $(\mathrm{h})(n=287)$} \\
\hline $\begin{array}{l}\text { Median } \\
\text { (IQR) }\end{array}$ & $\begin{array}{l}22 \\
(10-34)\end{array}$ & $\begin{array}{l}23 \\
(12-36)\end{array}$ & $\begin{array}{l}25 \\
(14-36)\end{array}$ & 0.71 \\
\hline \multicolumn{5}{|c|}{ bCPAP ventilation $(h)(n=200)$} \\
\hline $\begin{array}{l}\text { Median } \\
\text { (IQR) }\end{array}$ & $\begin{array}{l}16 \\
(0-38)\end{array}$ & $\begin{array}{l}19 \\
(0-38)\end{array}$ & $\begin{array}{l}8 \\
(0-38)\end{array}$ & 0.97 \\
\hline \multicolumn{5}{|c|}{ IMV (h) $(n=26)$} \\
\hline $\begin{array}{l}\text { Median } \\
\text { (IQR) }\end{array}$ & $\begin{array}{l}113 \\
(65-142)\end{array}$ & $\begin{array}{l}115 \\
(76-133)\end{array}$ & $\begin{array}{l}101 \\
(52-326)\end{array}$ & 1.0 \\
\hline \multicolumn{5}{|c|}{ PICU length of stay $(d)$} \\
\hline $\begin{array}{l}\text { Median } \\
\text { (IQR) }\end{array}$ & $\begin{array}{l}2.2 \\
(1.4-3.5)\end{array}$ & $2.1(1-3)$ & $3(1-4)$ & 0.06 \\
\hline \multicolumn{5}{|c|}{ Hospital length of stay (d) } \\
\hline $\begin{array}{l}\text { Median } \\
\text { (IQR) }\end{array}$ & $\begin{array}{l}4.5 \\
(3.2-6.7)\end{array}$ & $4(3-6)$ & $5(4-9)$ & 0.03 \\
\hline
\end{tabular}

Abbreviations: bCPAP, bubble continuous positive airway pressure; HFNC, high-flow nasal cannula; IMV, invasive mechanical ventilation; $\mathrm{IQR}$, interquartile range; $\mathrm{PICU}$, pediatric intensive care unit.

Table 3 Rate of three types of ventilatory support for cases with one virus compared to more than one virus

\begin{tabular}{|l|l|l|l|l|}
\hline & One virus & $\begin{array}{l}\text { More than } \\
\text { one virus }\end{array}$ & Total & $p$-Value \\
\hline HFNC & 203 & 84 & 287 & 0.6 \\
\hline No HFNC & 12 & 7 & 19 & \\
\hline Total & 215 & 91 & 306 & \\
\hline bCPAP & 147 & 53 & 200 & 0.11 \\
\hline No bCPAP & 68 & 38 & 106 & \\
\hline Total & 215 & 91 & 306 & \\
\hline IMV & 21 & 5 & 26 & 0.27 \\
\hline No IMV & 194 & 86 & 280 & \\
\hline Total & 215 & 91 & 306 & \\
\hline
\end{tabular}

Abbreviation: bCPAP, bubble continuous positive airway pressure ventilation; HFNC, high-flow nasal cannula; IMV, invasive mechanical ventilation.

The most commonly identified viruses in the group with one virus were RSV with $61 \%$ (133/215), picornavirus with $32 \%(68 / 215)$, and metapneumovirus with $3 \%(6 / 215)$ of cases. The most commonly identified viruses in the group with more than one virus were RSV with $27 \%$ (73/273), picornavirus with $26 \%(71 / 273)$, and adenovirus with $10 \%$ (27/273) of cases.

The rate of infants who presented to hospital with fever as part of their symptoms was 26\% (55/215) in the group with one virus and $24 \%$ (22/91) in the group of patients with more than one virus $(p=0.89)(-$ Table 4$)$. 
Table 4 Rate of fever on presentation for cases with one virus compared to more than one virus

\begin{tabular}{|l|l|l|l|l|}
\hline \multicolumn{6}{|l}{ Fever on presentation } \\
\cline { 1 - 4 } & One virus & More than one virus & Total & p-Value \\
\hline Yes & 55 & 22 & 77 & \multirow{2}{*}{0.89} \\
\cline { 1 - 4 } No & 160 & 69 & 229 & \\
\cline { 1 - 4 } Total & 215 & 91 & 306 & \\
\cline { 1 - 2 } & Odds ratio: 1.08 (95\% confidence interval: 0.61-1.91) \\
\hline
\end{tabular}

The rate of infants who had a secondary superimposed bacterial infection confirmed microbiologically was $12 \%$ (21/ $306)$, while the rate of infants who received antibiotics during their PICU admission was 73\% (222/306) (- Table 5).

\section{Discussion}

In this cohort of 306 infants admitted to PICU with viral bronchiolitis, $70 \%$ had one virus and $30 \%$ had more than one virus. This is similar to some reports from different parts of the world, but different to others were the figure presented here is higher than the 5 to $20 \%$ viral coinfection rate that has been reported. ${ }^{1-3,7}$ There was no difference between the two groups in terms of demographics or comorbidities, so based on these data it cannot be said that these have a role in causing infants to develop infections with more than one virus.

When analyzing the primary outcome, there was no difference in the total duration of respiratory support needed when infants had bronchiolitis due to one virus or more than one virus. This would add support to the argument that the number of viruses causing bronchiolitis does not alter the time that respiratory support is necessary. Therefore, we would not be able to use the number of viruses identified on NPA with PCR to predict how long infants would require respiratory support during PICU stay.

Table 5 Rate of confirmed superimposed bacterial infection and of use of empirical antibiotics for cases with one virus compared to more than one virus

\begin{tabular}{|c|c|c|c|c|}
\hline \multicolumn{5}{|c|}{ Confirmed superimposed bacterial infection } \\
\hline & One virus & More than one virus & Total & p-Value \\
\hline Yes & 12 & 9 & 21 & \multirow[t]{3}{*}{0.22} \\
\hline No & 203 & 82 & 286 & \\
\hline Total & 215 & 91 & 306 & \\
\hline \multicolumn{5}{|c|}{ Odds ratio: 0.54 (95\% confidence interval: $0.22-1.33$ ) } \\
\hline \multicolumn{5}{|c|}{ Received antibiotics } \\
\hline & One virus & More than one virus & Total & $p$-Value \\
\hline Yes & 161 & 61 & 222 & \multirow[t]{3}{*}{0.16} \\
\hline No & 54 & 30 & 84 & \\
\hline Total & 215 & 91 & 306 & \\
\hline
\end{tabular}

In this study, there was also no difference in the duration of respiratory support when using any type of delivery mode. The duration of respiratory support with each of the different delivery systems was similar in both groups. Not only was the duration of respiratory support similar, but also the rate of patients receiving HFNC, bCPAP, and IMV was also similar between the two groups. Infants in this cohort spent the most amount of time receiving respiratory support via HFNC, followed by bCPAP, and the least amount through IMV. It would seem that noninvasive methods of respiratory support, maybe HFNC more than bCPAP, deliver enough assistance during viral bronchiolitis to keep the majority of infants from requiring IMV. ${ }^{18-21}$ Avoiding the need of IMV is beneficial because induction of anesthesia and intubation is commonly associated with morbidity, including loss of lung volume and desaturation, and it requires the use of sedative agents, which have been associated with concerns about detrimental effects to the developing brain. ${ }^{22,23}$

Previous studies have shown that HFNC decreases the need for IMV. ${ }^{18}$ The reduced rate of IMV requirement seen here could possibly be a consequence of the effectiveness of HFNC rather than illness severity from the number of viruses causing bronchiolitis, but it is difficult to know just from looking at these data. The practices described here, of more noninvasive and less IMV, are consistent with current trends in the treatment of bronchiolitis throughout Australia and New Zealand. ${ }^{24}$

When looking at the PICU LOS, there was a trend toward longer LOS of almost 1 day for bronchiolitis cases with more than one virus, but that difference was not statistically significant. When analyzing hospital LOS, there was a significant difference of about 1 day more when cases of bronchiolitis were caused by more than one virus. Viral bronchiolitis is responsible for sequelae including recurrent wheezing and asthma. We also know that persistent immune activation can lead to chronic lung problems. ${ }^{25}$ It is possible that what we are seeing here are infants recovering from their acute illness relatively quickly, but still having a more intense immune response with persistent immune activation when bronchiolitis is due to more than one virus, which requires a longer hospital stay.

When looking at the viruses responsible for the illness, RSV was the most common pathogen in both groups, which is consistent with what is known and accepted about this condition. ${ }^{26}$ This report is also similar to others looking specifically at infants where picornavirus has been found as the causative pathogen with a similar frequency as found here. ${ }^{27}$ From these data, it would be difficult to make assumptions as to why this occurs in this way, but finding similar pathogens with similar frequencies, the results of this study could be generalized to the larger population of infants with this condition.

When looking at the prevalence of fever on presentation in both groups, there was no statistical difference between the groups. With both groups seeming to mount an inflammatory response at similar rates, and in the absence of a difference between duration of respiratory support or PICU LOS, it would seem that severity of illness is not affected by the number of viruses present at the time of infection. We are not assuming that all viruses behave or manifest themselves 
clinically in the same way, but we are unable to detect a difference from these data.

In this study, only $12 \%$ of children had confirmed superimposed bacterial infection with there being no difference between the two groups. Viral load does not seem to affect the likelihood of bacterial lower respiratory tract infection. This figure is consistent with current reports where the rate of secondary bacterial infection can range from $1.6 \%$ in the general infant population presenting with bronchiolitis to $40 \%$ in children with bronchiolitis receiving IMV. The specific pathogens and the rate at which they occurred were not identified, as this was not within the objectives of this study.

A high percentage of infants, 73\% (222/306), received empirical antibiotics in this cohort with there being no difference between the two groups. This is possibly because children can appear just as sick regardless of the number of viruses causing the illness. It is not uncommon that children with bronchiolitis receive empirical antibiotics with some studies reporting around $80 \%$ of nonintubated patients and $100 \%$ of intubated patients receiving antibiotics when at the same time less than $1 \%$ of screening cultures are positive for bacteria. ${ }^{28-30}$ This is a practice that seems to be widespread and is unlikely to change without more precise ways of determining the presence of bacterial infection at the beginning of the illness.

This study's strengths include its generalizability since the hospital where it was conducted receives a very wide and varied population that looks after every type of child. This study also includes a number of cases that is large enough to be able to produce a clear comparison between the two groups.

The limitations are that it is a single-center study and that it is difficult to eliminate selection bias. Mitigating this was attempted through including enough cases to minimize this.

When comparing infants under 1 year of age who have been admitted to PICU with viral bronchiolitis, the presence of one or more than one virus did not affect the duration of respiratory support through any means of delivery, did not affect the PICU LOS, did not affect the presence of superimposed bacterial infection, or the use of empirical antibiotics. It did however affect the hospital LOS, with cases who had more than one virus staying in hospital up to 1 day longer. This information can help clinicians and families understand these infections better.

\section{Note}

Ethics approval was waived by the Hunter New England Human Research Ethics Committee, who deemed the study as "Low or Negligible Risk."

The data sets used and/or analyzed during the current study are available from the corresponding author on reasonable request.

We an confirm all authors have met the ICMJE criteria for authorship on this study.

\section{Authors' Contributions}

T.C., A.T., H.C., and F.E.M. all contributed to the planning, conduct, and reporting of the study.

\section{Funding}

No funding was available for this study.

Conflict of Interest

None declared.

\section{References}

1 Richard N, Komurian-Pradel F, Javouhey E, et al. The impact of dual viral infection in infants admitted to a pediatric intensive care unit associated with severe bronchiolitis. Pediatr Infect Dis J 2008; 27(03):213-217

2 Oakley E, Chong V, Borland M, et al. Intensive care unit admissions and ventilation support in infants with bronchiolitis. Emerg Med Australas 2017;29(04):421-428

3 Mansbach JM, Piedra PA, Teach SJ, et al; MARC-30 Investigators. Prospective multicenter study of viral etiology and hospital length of stay in children with severe bronchiolitis. Arch Pediatr Adolesc Med 2012;166(08):700-706

4 Martin ET, Kuypers J, Wald A, Englund JA. Multiple versus single virus respiratory infections: viral load and clinical disease severity in hospitalized children. Influenza Other Respir Viruses 2012;6(01): 71-77

5 Janahi I, Abdulkayoum A, Almeshwesh F, Alkuwari M, Al Hammadi A, Alameri M. Viral aetiology of bronchiolitis in hospitalised children in Qatar. BMC Infect Dis 2017;17(01):139

6 Da Dalt L, Bressan S, Martinolli F, Perilongo G, Baraldi E. Treatment of bronchiolitis: state of the art. Early Hum Dev 2013;89(Suppl 1): S31-S36

7 Stempel HE, Martin ET, Kuypers J, Englund JA, Zerr DM. Multiple viral respiratory pathogens in children with bronchiolitis. Acta Paediatr 2009;98(01):123-126

8 Goka EA, Vallely PJ, Mutton KJ, Klapper PE. Single and multiple respiratory virus infections and severity of respiratory disease: a systematic review. Paediatr Respir Rev 2014;15(04):363-370

9 Trenholme AA, Best EJ, Vogel AM, Stewart JM, Miller CJ, Lennon DR. Respiratory virus detection during hospitalisation for lower respiratory tract infection in children under 2 years in South Auckland, New Zealand. J Paediatr Child Health 2017;53(06):551-555

10 Calvo C, García-García ML, Blanco C, et al. Multiple simultaneous viral infections in infants with acute respiratory tract infections in Spain. J Clin Virol 2008;42(03):268-272

11 Brand HK, de Groot R, Galama JM, et al. Infection with multiple viruses is not associated with increased disease severity in children with bronchiolitis. Pediatr Pulmonol 2012;47(04):393-400

12 Flores-González JC, Mayordomo-Colunga J, Jordan I, et al. Prospective multicentre study on the epidemiology and current therapeutic management of severe bronchiolitis in Spain. Biomed Res Intl 2017;2017:2565397

13 Mansbach JM, Piedra PA, Stevenson MD, et al; MARC-30 Investigators. Prospective multicenter study of children with bronchiolitis requiring mechanical ventilation. Pediatrics 2012;130(03):e492-e500

14 Bordley WC, Viswanathan M, King VJ, et al. Diagnosis and testing in bronchiolitis: a systematic review. Arch Pediatr Adolesc Med 2004;158(02):119-126

15 Fitzgerald DA, Kilham HA. Bronchiolitis: assessment and evidence-based management. Med J Aust 2004;180(08):399-404

16 Ralston SL, Lieberthal AS, Meissner HC, et al; American Academy of Pediatrics. Clinical practice guideline: the diagnosis, management, and prevention of bronchiolitis. Pediatrics 2014;134(05): e1474-e1502

17 Moesker FM, van Kampen JJ, van Rossum AM, et al. Viruses as sole causative agents of severe acute respiratory tract infections in children. PLoS One 2016;11(03):e0150776

18 Schibler A, Pham TMT, Dunster KR, et al. Reduced intubation rates for infants after introduction of high-flow nasal prong oxygen delivery. Intensive Care Med 2011;37(05):847-852 
19 Pham TMT, O'Malley L, Mayfield S, Martin S, Schibler A. The effect of high flow nasal cannula therapy on the work of breathing in infants with bronchiolitis. Pediatr Pulmonol 2015;50(07):713-720

20 Frat J-P, Thille AW, Mercat A, et al; FLORALI Study Group; REVA Network. High-flow oxygen through nasal cannula in acute hypoxemic respiratory failure. N Engl J Med 2015;372(23):2185-2196

21 Donlan M, Fontela PS, Puligandla PS. Use of continuous positive airway pressure (CPAP) in acute viral bronchiolitis: a systematic review. Pediatr Pulmonol 2011;46(08):736-746

22 Sanders RD, Hassell J, Davidson AJ, Robertson NJ, Ma D. Impact of anaesthetics and surgery on neurodevelopment: an update. $\mathrm{Br} \mathrm{J}$ Anaesth 2013;110(Suppl 1):i53-i72

23 Wilder RT, Flick RP, Sprung J, et al. Early exposure to anesthesia and learning disabilities in a population-based birth cohort. Anesthesiology 2009;110(04):796-804

24 Schlapbach LJ, Straney L, Gelbart B, et al; Australian \& New Zealand Intensive Care Society (ANZICS) Centre for Outcomes \& Resource Evaluation (CORE) and the Australian \& New Zealand Intensive Care Society (ANZICS) Paediatric Study Group. Burden of disease and change in practice in critically ill infants with bronchiolitis. Eur Respir J 2017;49(06):1601648
25 Vandini S, Calamelli E, Faldella G, Lanari M. Immune and inflammatory response in bronchiolitis due to respiratory syncytial virus and rhinovirus infections in infants. Paediatr Respir Rev 2017;24:60-64

26 Florin TA, Plint AC, Zorc JJ. Viral bronchiolitis. Lancet 2017;389 (10065):211-224

27 Jartti T, Lehtinen P, Vuorinen T, et al. Respiratory picornaviruses and respiratory syncytial virus as causative agents of acute expiratory wheezing in children. Emerg Infect Dis 2004;10(06): 1095-1101

28 Thorburn K, Harigopal S, Reddy V, Taylor N, van Saene HKF. High incidence of pulmonary bacterial co-infection in children with severe respiratory syncytial virus (RSV) bronchiolitis. Thorax 2006;61(07):611-615

29 Randolph AG, Reder L, Englund JA. Risk of bacterial infection in previously healthy respiratory syncytial virus-infected young children admitted to the intensive care unit. Pediatr Infect Dis J 2004;23(11):990-994

30 Purcell K, Fergie J. Concurrent serious bacterial infections in 2396 infants and children hospitalized with respiratory syncytial virus lower respiratory tract infections. Arch Pediatr Adolesc Med 2002;156(04):322-324 